
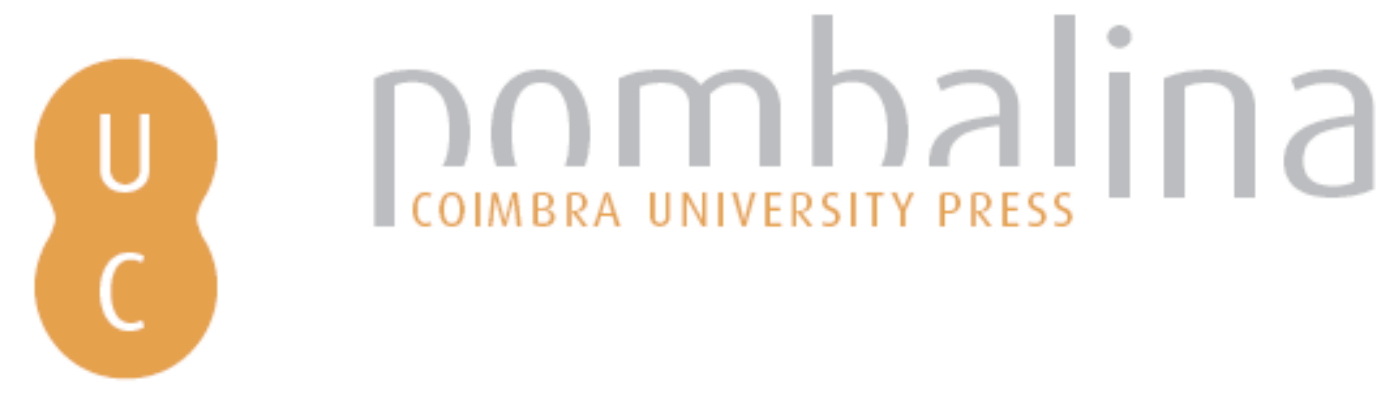

\title{
Effects of aerodynamic lift on firebrand trajectories: numerical investigations based on simplified models
}
Autor(es):
Zhou, Hangxu; Li, Yi; Zhang, Yang
Publicado por: Imprensa da Universidade de Coimbra
URL
persistente:
URI:http://hdl.handle.net/10316.2/44562
DOI:
DOI:https://doi.org/10.14195/978-989-26-16-506_45
Accessed : $\quad$ 26-Apr-2023 03:31:40

A navegação consulta e descarregamento dos títulos inseridos nas Bibliotecas Digitais UC Digitalis, UC Pombalina e UC Impactum, pressupõem a aceitação plena e sem reservas dos Termos e Condições de Uso destas Bibliotecas Digitais, disponíveis em https://digitalis.uc.pt/pt-pt/termos.

Conforme exposto nos referidos Termos e Condições de Uso, o descarregamento de títulos de acesso restrito requer uma licença válida de autorização devendo o utilizador aceder ao(s) documento(s) a partir de um endereço de IP da instituição detentora da supramencionada licença.

Ao utilizador é apenas permitido o descarregamento para uso pessoal, pelo que o emprego do(s) título(s) descarregado(s) para outro fim, designadamente comercial, carece de autorização do respetivo autor ou editor da obra.

Na medida em que todas as obras da UC Digitalis se encontram protegidas pelo Código do Direito de Autor e Direitos Conexos e demais legislação aplicável, toda a cópia, parcial ou total, deste documento, nos casos em que é legalmente admitida, deverá conter ou fazer-se acompanhar por este aviso.

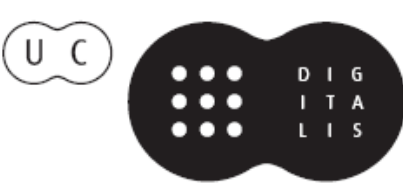




\section{ADVANCES IN}

\section{FOREST FIRE RESEARCH}

\section{8}

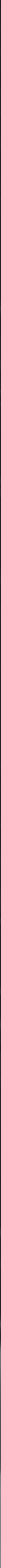




\title{
Effects of aerodynamic lift on firebrand trajectories: Numerical investigations based on simplified models.
}

\author{
Hangxu Zhou'; Yi Li ${ }^{2}$; Yang Zhang*1 \\ ${ }^{1}$ Department of Mechanical Engineering, University of Sheffield, Sheffield, S1 4DF, UK, \\ \{hzhou1@sheffield.ac.uk, yz100@sheffield.ac.uk*\} \\ ${ }^{2}$ School of Mathematics and Statistics, University of Sheffield, Sheffield, S3 7RH, UK, \\ \{yili@sheffield.ac.uk\}
}

\begin{abstract}
Spotting distance of a firebrand lofted in flow is an important mechanism of fire spread in large scale fires such as forest fires. Many models have been developed to study the propagation of a firebrand, but only a few focused on analyzing the aerodynamic lift on firebrand trajectories. From the modelling perspective, it is important to ascertain the relative importance of the lift compared with the drag force. However, no such study has been reported. In this paper, simplified models are developed to illustrate the effects of the lift on the maximum potential propagation distances of rectangular-shaped firebrands. The effects are firstly demonstrated clearly for non-burning firebrands. The effects of size regression and mass loss on burningparticle are then considered. A variable-thickness-burning model is developed to account for these effects. Two lift coefficient models, suitable for different Reynolds numbers, are considered. The results demonstrate that the lift force can have very significant effects on the firebrand trajectories. Using the high Reynolds number lift model, the spotting distance can be increased up to 14 times of the traveling distances calculated without the lift. Positive effects are found over whole ranges of parameters. On the other hand, when the low Reynolds number model is used, occasionally the lift can have very small negative effects, especially for the firebrands at large ambient flow velocities. By comparing with the results of variable-thickness-burning model, it is obtained that lift effects are sensitive to the inertia of a firebrand at small Reynolds and large flow velocity. Finally, for the parameters involved in this study, attempts are made to compare their importance to the effects of the lift. The main factor is found to be the ambient flow velocity which can significantly enhance or weaken the lift effects. Another main factor is the incident angle. The lift effects are strengthened at negative angles but weakened at positive ones. The lift effects are relatively weaker for higher particle density, whereas they are mostly independent of particle initial velocity. We conclude that the lift force has very significant effects on particle propagations, and should be considered in order to model extreme spotting distances.
\end{abstract}

Keywords: firebrands, trajectory, aerodynamic lift, numerical models.

\section{Introduction}

Spotting ignition has been found to be a significant mechanism of fire spreads since at least the 1960s (Tarifa et al, 1965). The flaming or glowing pieces of wood, branches, or charcoal etc., commonly called firebrands, are lofted by a fire plume and transported by wind to cause new ignition in large-scale fire. It has been shown that firebrands contribute to the spread of large-scale fires such as the 1666 London Fire, the 1871 Chicago Fire, the 1923 Tokyo Fire, the 2006 Iversen Fire, etc (Koo, 2010). The short-distance spotting firebrands, such as barks, needles, leaves and small wood particles, can continuously keep the fire spreading, while the long-distance spots, such as glowing charcoal, may result in new spot ignition which is kilo meters ahead of the main fire. The latter also is the main cause that decreases the efficiency of forest fire prevention methods used nowadays, such as firebreaks and fire resistance barriers. Predicting the spotting of firebrands is considered one of the most difficult, yet important problems in the study of fire spread, since it involves a board range of physical processes including generation of firebrands, transport, and ignition of fuel at the landing position. To predict 
firebrand transport, it requires the analyses of the aerodynamics and combustion of firebrands under various fluid and weather conditions, and the associated convective plume with different fire intensities. The present work focuses on the transport of firebrands, in particular the effects of aerodynamic lift. The mechanisms of the other two processes, i.e., the generation of firebrands and the potential ignition of fuel at the landing position, are not considered.

In 1965, the transport of firebrands in combustion were firstly studied by Tarifa et al (Tarifa et al, 1965). For burning particles tested in wind tunnels, including spherical and cylindrical shapes, the lifetime, the laws of variation of weight, and aerodynamic drag were determined as functions of time. Flight paths of firebrands were calculated for prescribed wind conditions. Parameters of particles, including initial shape, size, kind of wood and moisture content, were deduced in theoretical calculations. Models for the transport of spherical firebrands with convective plume were developed by Lee and Hellman in 1970 (Lee and Hellman, 1970). The trajectories of wood spheres in axisymmetric swirling convective plume were analysed and compared with Tarifa's results. Similar paths but shorter spotting distances were found. Models of cylindrical firebrands released in a fire swirl were developed by Muraszew et al (Muraszew et al, 1977). The aerodynamic behaviours of cylindrical firebrands were modelled differently in three regions, and the rotation of particles were calculated. The density variation of the cylindrical firebrands was found to be exponential in time and the diameter regression rate. Basing on the work of Muraszew, the burning rates of various shapes were modelled by Albini (Albini, 1979). Diameter regression rate was determined as a constant $(K=$ 0.0064). A linear equation was developed to describe the change of terminal velocity due to the changes of the density and the diameter of falling flaming firebrands. Models of cylindrical firebrands lofted by torching trees were developed to predict the trajectories and maximum spotting distance. Further, he studied the transport of firebrands by line thermal and modelled the behaviour of a strong line thermal.

Lift effects on the propagation of firebrands were firstly considered by Woycheese et al (1999). The maximum spotting distances of disk-shaped firebrands over Baum and McCaffrey plume were calculated. Constant angle of attack between disk and relative wind was assumed. The enhancement of firebrand propagation by the lift was observed. Besides, a large number of experiments were conducted by Woycheese et al to investigate the behaviour of lofted firebrands, including the trajectories of nonburning and combusting spheres, and wood brands of various geometries. However, the lift force was included in the integration of the aerodynamic trajectories of firebrands only in a few works (Himoto et al, 2005; Sardoy, 2007). A transport model for a disk-shaped firebrand in 3D space was developed by Himoto, which was integrated alongside a Large Eddy Simulation of a buoyancy flow. In his work, the lift coefficient was calculated by an empirical formula valid at Reynolds numbers around 40000. Sardoy developed a numerical model for the transport of burning brands lofted in a crown fire. A combustion model was discussed in detail including the analyses of both pyrolysis rate and char oxidation rate.

The above brief review shows that the aerodynamic lift, as an important factor of particle transport, has been largely missing in the models for the motion of the firebrands. The research focused on the effect of aerodynamic lift force during particle propagations is especially scarce since the enhancement effects from lift on spotting was found by Woycheese et al. This paper focuses on using simplified models to highlight the effects of aerodynamic lift force on the motion of both non-burning and burning firebrands, in particular their relative importance compared with the drag force. The effects of a broad range of properties, including the Reynolds number, the ambient flow velocity, the particle initial velocity and the incident angle of particle relative to ambient flow, are investigated and compared with each other. Based on the maximum potential spotting distance determined, the lift effects are discussed in details. 


\section{Conceptualisation of models}

\subsection{Transport of firebrands}

In the transport phase of firebrands spotting phenomenon, a mathematical model for determining the trajectory and predicting the maximum potential spotting distance is developed. When the firebrand exits main fire region and then glides in a constant flow field, shown in Fig. 1, it is no longer affected by the plume from the main fire but supported by aerodynamic drag and lift forces. The coordinate system can be simplified into two-dimensional with the assumptions that a rectangular-shaped firebrand obeys axisymmetric aerodynamic behaviours during propagation.

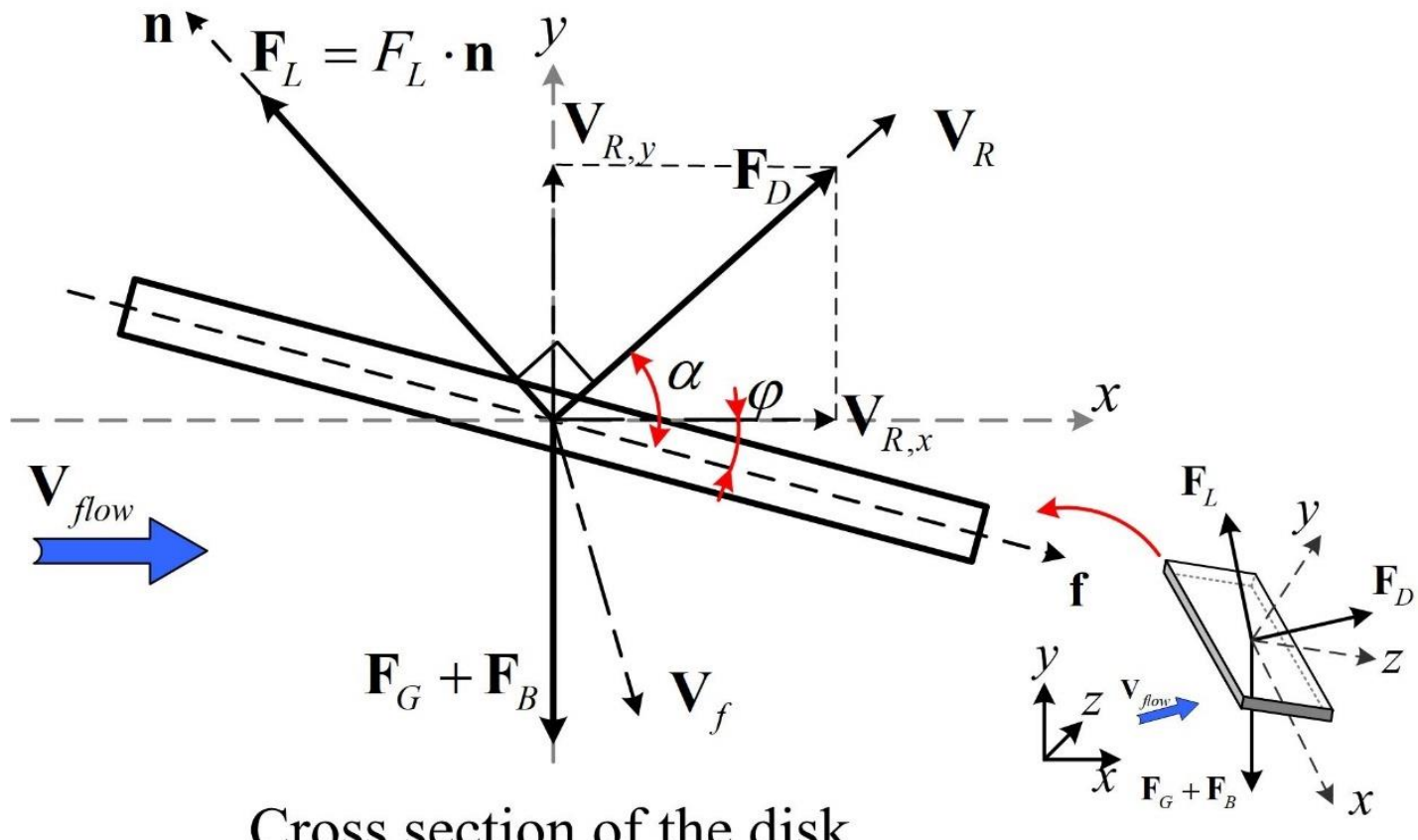

Figure 1 - Schematic representation of the transport model of a disk-shaped firebrand in the flow field.

$\mathbf{V}_{\mathrm{f}}, \mathbf{V}_{\text {flow }}$ and $\mathbf{V}_{\mathrm{R}}$ indicate the velocity of firebrands, ambient flow velocity due to wind, and the relative velocity between disk and air flow, respectively. The angle of attack is denoted by, $\alpha$, which is the angle between disk and relative velocity, whereas the incident angle, $\varphi$, indicates the angle between the disk and the horizontal direction. The direction vectors $\mathbf{f}$ and $\mathbf{n}$ represent the directions along the firebrand and the direction of lift force respectively.

This numerical model is based on the following assumptions:

1) This work focuses on determining the trajectories of firebrands in the transport phase of the spotting phenomenon of firebrands. The particle is assumed to have already exited the main fire zone and is released from $100 \mathrm{~m}$ above ground in air. The plume due to the forest fire in main fire zone is not concluded, and the ambient flow field due to wind is assumed to be constant in each testing cases but a board range of flow velocities are tested.

2) Firebrands are idealized as rectangular-shape disks with aspect ratio 1.6, and it is assumed that the orientation of the disk remains the same during the propagation. That is, the rotation and vibrations of the firebrand, such as tumbling and wobbling, are neglected.

3) As a simplified model to determine maximum spotting distance of firebrands, the aerodynamic effects of combustion on firebrands are beyond the scope of this paper. These include the effects on aerodynamic lift and drag coefficients due to flaming, which are neglected. According to the study by Tse and Fernande-Pello (Tse and Fernandez-Pello, 1998), the surface reaction of burning particles were enhanced at high Reynolds number and were not susceptible 
to be extinguished. The situation of flame extinction is thus not considered. The life time of a burning particle is determined based on size regression and mass loss rate.

4) It is assumed that the brands hold the shapes unchanged in combustion. Two models of burning particles have been used based on different assumptions on the changes of particle thickness in combustion. In the first one the thickness is assumed to be constant (Anthenien et al, 2006), whereas in the other it is variable over time and is calculated basing on the burning constant.

5) This work aims to obtain the trajectory and the maximum sporting distance of firebrand by considering limiting cases. The upper bonds of the parameter in this study are, for ambient flow velocity, $10 \mathrm{~m} / \mathrm{s}$, for density, $950 \mathrm{~kg} / \mathrm{m}^{3}$, and for initial particle velocity, $1.0 \mathrm{~m} / \mathrm{s}$.

\subsubsection{Aerodynamic forces}

Aerodynamic forces exerted on the disk-shaped firebrand transporting in flow include the drag force, $\mathbf{F}_{\mathrm{D}}$, the lift force, $\mathbf{F}_{\mathrm{L}}$, and the gravity combined with buoyancy, $\mathbf{F}_{\mathrm{G}}+\mathbf{F}_{\mathrm{B}}$, as shown in Fig. 1 . The net force on the firebrand thus can be expressed as

$$
\boldsymbol{F}=\boldsymbol{F}_{D}+\boldsymbol{F}_{L}+A \tau\left(\rho_{f}-\rho_{\text {flow }}\right) \boldsymbol{g}
$$

where $\mathbf{F}_{\mathrm{D}}$ and $\mathbf{F}_{\mathrm{L}}$ indicate the aerodynamic drag and lift forces respectively. The virtual mass force and the time-history effects (Yin et al, 2003) are both neglected. In terms of the relative velocity, $\mathbf{V}_{R}$, and the vector along the firebrand, $\mathbf{f}$, the lift force can be expressed as $\mathbf{V}_{\mathrm{R}} \cdot \mathbf{f}$. Taking into account the fact that the agnle of attak isin the range of $\left[-90^{\circ}, 90^{\circ}\right]$, the direction vecotor of the lift force, $\mathbf{n}$, points in the same direction as the following vector:

$$
\left(\boldsymbol{V}_{R} \cdot \boldsymbol{f}\right)\left(\boldsymbol{f} \times \boldsymbol{V}_{R}\right) \times \boldsymbol{V}_{R}
$$

The movment in the third direction is negelcted. The full expression of $\mathbf{n}$ can be presented based on the incident angle, $\varphi$, shown as:

$$
\boldsymbol{n}=\left(V_{R, x} \cos \varphi+V_{R, y} \sin \varphi\right)\left(V_{R, y} \cos \varphi-V_{R, x} \sin \varphi\right) \cdot \frac{-v V_{R, y} \boldsymbol{i}+V_{R, x} \boldsymbol{j}}{\sqrt{V_{R, x}{ }^{2}+V_{R, y}{ }^{2}}}
$$

where the sign of the first term on the right hand side characterises the direction of $\mathbf{n}$. Meanwhile, the angle of attack, $\alpha$, can be calculated based on both vectors, as follows:

$$
\alpha=\arccos \frac{\left|\boldsymbol{V}_{R} \cdot \boldsymbol{f}\right|}{\left|\boldsymbol{V}_{R}\right|}
$$

Note that both the drag and lift forces will be zero if the relative velocity is parallel to the direction of the disk (when $\alpha=0^{\circ}$ ), due to the relatively small thicknesses of the firebrands tested. Finally, the aerodynamic drag and lift forces extered on the firebrand then can be expressed as

$$
\begin{aligned}
& \boldsymbol{F}_{D}=\frac{1}{2} C_{D} \rho_{\text {flow }} A\left|\boldsymbol{V}_{R}\right| \boldsymbol{V}_{R} \\
& \boldsymbol{F}_{L}=\frac{1}{2} C_{L} \rho_{\text {flow }} A\left(\boldsymbol{V}_{R}\right)^{2} \boldsymbol{n}
\end{aligned}
$$

where $A$ is the objective area of the firebrand. $C_{D}$ and $C_{L}$, respectively, denote the aerodynamic coeffcients of drag and lift. Considering the range of Reyonlds number can be as large as $2 \times 10^{5}$, different aerodynamic coeffcients have been used to check the sensitivity of the calculations. For relatively low Reynolds number, $\operatorname{Re}<10^{3}$, the formular given in Zastawny et al (Zastawny et al, 2012), are used: 


$$
\begin{aligned}
& C_{D}(\alpha)=\frac{5.82}{R e^{0.44}}+\frac{15.56}{R e^{1.068}}+\left(\frac{35.41}{R e^{0.96}}+\frac{3.63}{R e^{0.05}}-\frac{5.82}{R e^{0.44}}+\frac{15.56}{R e^{1.068}}\right) \sin ^{1.96}(\alpha) \\
& C_{L}=\left(\frac{12.111}{R e^{1.036}}+\frac{3.887}{R e^{0.109}}\right) \sin (\alpha)^{0.812+0.249 R e^{-0.198}} \cos (\alpha)^{5.821-4.7179 R e^{0.007}}
\end{aligned}
$$

Meanwhlie, the aerodynamic drag and lift coeffcients for higher Reynolds number, up to $2 \times 10^{5}$, was determined by Ortiz et al (Ortiz et al, 2015). The comparison with Zastawny's data showed that the drag coeffcients showed similar trends with increasing angle of attack although with slightly different values. The proposed emprical fits can be expressed as:

$$
\begin{aligned}
& C_{D}(\alpha)=-a\left(\frac{\alpha-45}{26.413}\right)^{3}-b\left(\frac{\alpha-45}{26.413}\right)^{2}+c\left(\frac{\alpha-45}{26.413}\right)+d \\
& C_{L_{\alpha \leq 35^{\circ}}}=-0.0014086 \times \alpha^{2}+0.068014 \times \alpha-5.8984 \times 10^{-16} \\
& C_{L_{35^{\circ}<\alpha \leq 50^{\circ}}}=-e\left(\frac{\alpha-42.5}{6.455}\right)^{2}-f\left(\frac{\alpha-42.5}{6.455}\right)+g \\
& C_{L_{50^{\circ}<\alpha \leq 90^{\circ}}}=-h\left(\frac{\alpha-42.5}{6.455}\right)^{2}-k\left(\frac{\alpha-42.5}{6.455}\right)+n
\end{aligned}
$$

where the constants $\mathrm{a}, \mathrm{b}, \mathrm{c}$ and $\mathrm{d}$ are given as $0.02829,0.04068,0.37165$ and 0.68864 respectively. For the lift coefficient, the constants e, f, g, h, $\mathrm{k}$ and $\mathrm{n}$ are $0.03125,0.01097,0.68219,6.711 \times 10^{5}$, 0.00632 and 1.1113 .

\subsubsection{Equations of motion}

Trajectories of the firebrands are determined from Newton's second law of motion, shown here as:

$$
m_{f} \frac{d V_{f}}{d t}=F_{D}+F_{L}+A \tau\left(\rho_{f}-\rho_{\text {flow }}\right) g
$$

The equation above can be resolved, respectively, in the $\mathrm{x}$ - and $\mathrm{y}$-directions as:

$$
\begin{aligned}
& m_{f} \frac{d V_{f, x}}{d t}=\frac{1}{2} C_{D} \rho_{\text {flow }} A\left|\boldsymbol{V}_{R}\right|\left|\boldsymbol{V}_{R, x}\right|+\frac{1}{2} C_{L} \rho_{\text {flow }} A \boldsymbol{V}_{R}{ }^{2}\left|\boldsymbol{n}_{x}\right| \\
& m_{f} \frac{d V_{f, y}}{d t}=\frac{1}{2} C_{D} \rho_{\text {flow }} A\left|\boldsymbol{V}_{R}\right|\left|\boldsymbol{V}_{R, y}\right|+\frac{1}{2} C_{L} \rho_{\text {flow }} A \boldsymbol{V}_{R}{ }^{2}\left|\boldsymbol{n}_{y}\right|-A \tau\left(\rho_{f}-\rho_{\text {flow }}\right) g
\end{aligned}
$$

A range of initial velocities is tested to determine the effects of particle initial velocity on spotting distance. The vertical component of the initial velocity is set as zero.

\subsection{Simplified combustion models of firebrands}

Two simplified combustion models, based on different assumptions on the behaviours of the thickness of the firebrands, are used to simulate the size regression rate and mass loss rate of the disks outside of the main fire zone. Since no published experimental data are available for the burning of rectangular-shaped disks, the most relevant calculations are found from Tarifa et al (1965), where the burning behaviours of spherical-shaped disks were presented in terms of the burning constant and the 'd-squared law', which can be written as:

$$
\frac{d\left(D_{e f f}^{2}\right)}{d t}=-\beta
$$


where $\beta$ is the dimensionless burning constant and $D_{\text {eff }}$ denotes the effective mass diameter of firebrands. Further, the modified burning constant was derived by Williams (Williams, 1985) as a function of the Reynolds number and the Prandtl number, shown below:

$$
\beta=\beta_{0}\left(1+0.276 \operatorname{Re}^{\frac{1}{2}} \operatorname{Pr}^{\frac{1}{3}}\right)
$$

where the value of $\beta_{0}$ has been found to be $1.8 \times 10^{-7}$. With the assumption that the thickness of the disk is constant, the proposed mass loss rate based the derivations above can be found from Anthenien et al (Anthenien et al, 2006) as:

$$
\frac{d(m)}{d t}=-\frac{\pi}{4} \tau \beta_{0} \rho_{f}\left(1+0.276 \operatorname{Re}^{\frac{1}{2}} \operatorname{Pr}^{\frac{1}{3}}\right)
$$

On the other hand, if we consider the change of thickness in combustion, the equation of the size regression rate can be derived as:

$$
\frac{d(m)}{d t}=-\frac{\pi}{4} \rho_{f}\left(\frac{6 m}{\rho_{f} \pi}\right)^{\frac{1}{3}} \beta_{0}\left(1+0.276 \operatorname{Re}^{\frac{1}{2}} \operatorname{Pr}^{\frac{1}{3}}\right)
$$

Although the geometry utilised in this model is a rectangular-shaped disk, other than the spherical disk in Anthenien's work, the reaction is still diffusion controlled, which justifies our derivation.

\section{Results and discussions}

\subsection{Computational details}

Over 4122 cases from 72 sets of simulations are investigated in this work to determine the lift effects on the firebrand for various working parameters, including the ambient flow velocity, the particle initial velocity, the incident angle and the density of firebrands. The maximum spotting distance of each brand, released from $100 \mathrm{~m}$ in height, is determined by its horizontal displacement once it hits the ground. Meanwhile, the position and the velocity of the tested firebrand as function of time are calculated from the equations of motion discussed above. The initial dimension of the tested firebrand is set as $80 \mathrm{~mm} \times 50 \mathrm{~mm} \times 5 \mathrm{~mm}$ based on the data of real firebrands found from Oakland Hill Fire (Koo, 2010). The tested range of wind speed is $[0,10](\mathrm{m} / \mathrm{s})(\approx 22.4 \mathrm{mph})$, the initial velocities of the firebrands are in the interval $[0,1](\mathrm{m} / \mathrm{s})$ and the range of the incident angle is $\left[-90^{\circ}, 90^{\circ}\right]$. Considering the various possible wood species in real forest fire, a broad range of density is used, from $250 \mathrm{~kg} / \mathrm{m}^{3}$, typical of wood charcoal, to $950 \mathrm{~kg} / \mathrm{m}^{3}$, typical of satinwood. 


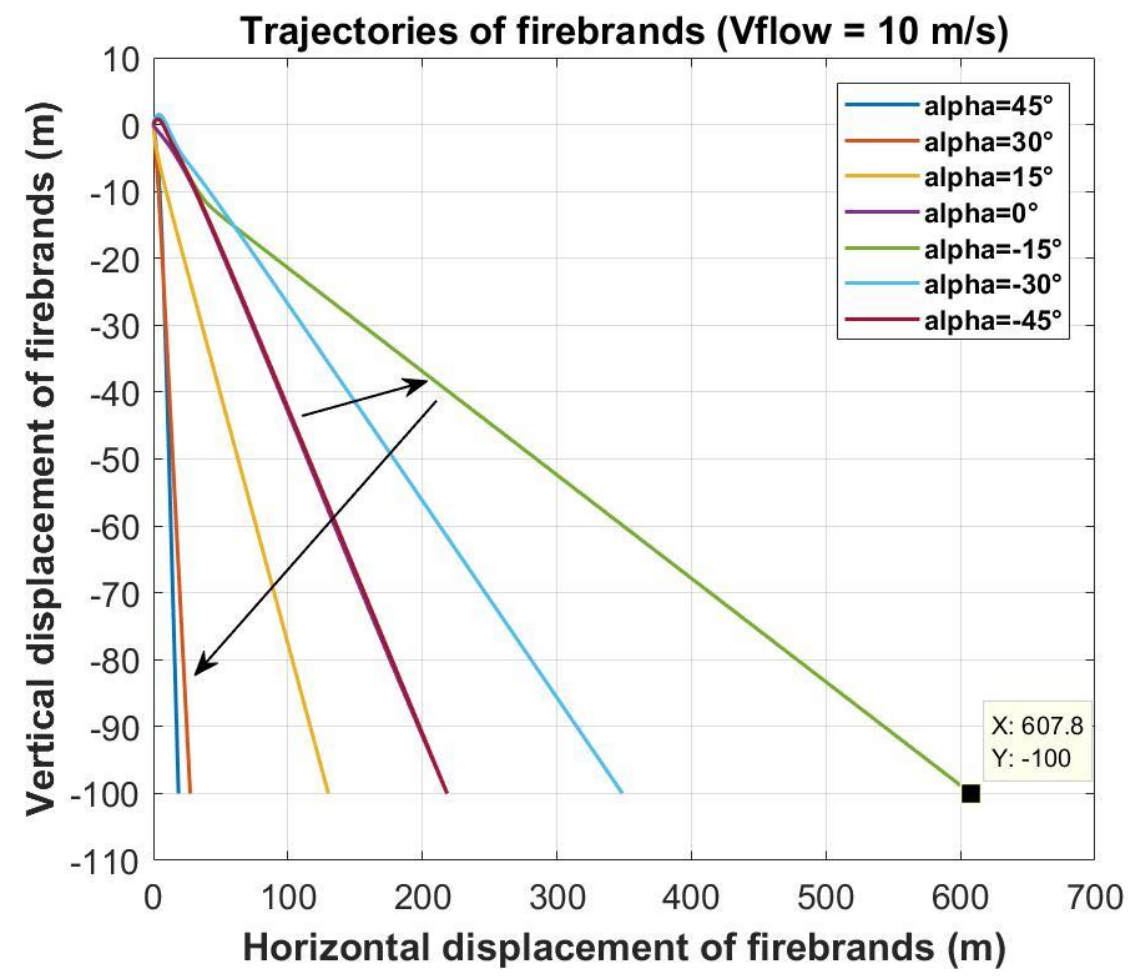

Figure 2 - Trajectories of firebrands at various incident angles with ambient wind velocity of $10 \mathrm{~m} / \mathrm{s}$.

Fig. 2 presents an example of the trajectories of the firebrand at various incident angles with $\mathrm{V}_{\text {flow }}$ $=10 \mathrm{~m} / \mathrm{s}$. It can be seen that the spotting distance and trajectory of a firebrand are highly dependent on the incident angle. The peak spotting distance occurs at the incident angle $-15^{\circ}$, which is a common feature covering most cases, except for non-burning firebrands and burning firebrands with constant thickness, where the peaks are found at $-30^{\circ}$. The 'lift-up', up to $2 \mathrm{~m}$, can be found at the early stage of propagation for all cases of negative incident angle. This behaviour is because the resultant force on upward direction is greater than the gravity, which quickly decreases with the change of angle of attack due to the increasing velocities on both directions.

\subsection{Effects of models}

A dimensionless 'Glide ratio' is used to describe and compare the spotting distance for each tested firebrand. The Glide ratio is the ratio of horizontal displacement over vertical displacement at the firebrand's landing. As shown in Table 1, a broad range of Glide ratios are found, from about 0 to 6.091. Very similar results are obtained from the non-burning and constant-thickness-burning models. This is because of the very small value of area regression rate in constant-thickness-model, which is around $7 \times 10^{-6} \mathrm{~m}^{2} / \mathrm{s}$ when Re is around $1 \times 10^{5}$. Little change of firebrand's propagation is observed due to such small size change. However, enhanced propagation distances are found for the variablethickness-burning models, which average about 0.01 larger with the large Reynolds number models and 0.134 larger with the small Reynolds number model. It proves that the considerations of thickness change can have significant impact on the calculations of firebrands propagations, especially for the cases with moderate Reynolds numbers.

More importantly, the very significant effects of aerodynamic lift on firebrands propagation are demonstrated by the results in the table, that the lift force can drastically increase the propagation distances of the firebrands with or without combustion, for different Reynolds numbers. The increase in GR can be as large as $3.845(171.19 \%)$, as is shown in the $4^{\text {th }}$ column of the table, which means 384.5 meters further in horizontal displacement for a firebrand falling from 100 meters in height. The vertical falling speed of a firebrand is decreased by lift force while the horizontal speed is increased, which result in the firebrands having not only larger horizontal speed but also longer flight time. 
Furthermore, it can be observed that the positive lift effects are increased in the variable-thicknessburning model. For a burning firebrand, although the magnitude of lift force is reduced due to area regression, the lose of weight creates a chance to glide further. However, it is also found that lift force has negative effects on propagations when the lift formula for lower Reynolds number is used, shown with the negative values highlighted in blue in Table 1. This is due to the combination of two effects. Firstly, stronger effects from the drag force are found for smaller Reynolds numbers (smaller coefficient of lift comparing to drag). Secondly, the change of angle of attack due to the increases in velocities is more sensitive (the direction of the lift force could quickly change from pointing upward to pointing downward), resulting in longer flight time when the lift is absence even though velocities are smaller.

Table 1 - Maximum Glide ratios of tested firebrands with different variables

\begin{tabular}{|c|c|c|c|c|c|c|}
\hline \multirow{3}{*}{$\begin{array}{c}\text { Independent } \\
\text { Variables }\end{array}$} & \multicolumn{6}{|c|}{ Max Glide Ratio (GR = horizontal displacement / vertical displacement) } \\
\hline & \multicolumn{3}{|c|}{ Large Reynolds Number Model } & \multicolumn{3}{|c|}{ Small Reynolds Number Model } \\
\hline & Lift + Drag & Drag only & Lift effect & Lift + Drag & Drag only & Lift effect \\
\hline \multicolumn{7}{|c|}{ Non-burning firebrands } \\
\hline $\begin{array}{l}\text { Flow velocity, } V_{\text {flow }} \& \\
\text { Incident angle, } \varphi\end{array}$ & 6.078 & 2.269 & 3.809 & 4.062 & 4.095 & -0.033 \\
\hline $\begin{array}{l}\text { Flow velocity, } V_{\text {flow }} \& \\
\text { Initial velocity, } V_{f, 0}\end{array}$ & 6.078 & 2.250 & 3.828 & 4.062 & 4.009 & -0.053 \\
\hline $\begin{array}{c}\text { Flow velocity, } V_{\text {flow }} \& \\
\text { Density, } \rho\end{array}$ & 6.078 & 2.246 & 3.832 & 4.062 & 4.006 & 0.056 \\
\hline $\begin{array}{l}\text { Incident angle, } \varphi \& \\
\text { Initial velocity, } V_{\mathrm{f}, 0}\end{array}$ & 2.430 & 0.019 & 2.411 & 0.919 & 0.026 & 0.893 \\
\hline $\begin{array}{c}\text { Incident angle, } \varphi \& \\
\text { Density, } \rho\end{array}$ & 2.379 & $<0.001$ & 2.379 & 0.904 & $<0.001$ & 0.904 \\
\hline $\begin{array}{c}\text { Density, } \rho \& \\
\text { Initial velocity, } V_{\mathrm{f}, 0}\end{array}$ & 2.430 & 0.014 & 2.416 & 0.173 & $<0.001$ & 0.173 \\
\hline \multicolumn{7}{|c|}{ Burning firebrands (constant thickness) } \\
\hline $\begin{array}{l}\text { Flow velocity, } V_{\text {flow }} \& \\
\text { Incident angle, } \varphi\end{array}$ & 6.078 & 2.269 & 3.809 & 4.062 & 4.095 & -0.033 \\
\hline $\begin{array}{l}\text { Flow velocity, } V_{\text {flow }} \& \\
\text { Initial velocity, } V_{f, 0}\end{array}$ & 6.078 & 2.250 & 3.828 & 4.062 & 4.009 & -0.053 \\
\hline $\begin{array}{c}\text { Flow velocity, } V_{\text {flow }} \& \\
\text { Density, } \rho\end{array}$ & 6.078 & 2.246 & 3.832 & 4.062 & 4.006 & 0.056 \\
\hline $\begin{array}{l}\text { Incident angle, } \varphi \& \\
\text { Initial velocity, } V_{\mathrm{f}, 0} \\
\end{array}$ & 2.430 & 0.019 & 2.411 & 0.919 & 0.026 & 0.893 \\
\hline $\begin{array}{c}\text { Incident angle, } \varphi \& \\
\text { Density, } \rho\end{array}$ & 2.379 & $<0.001$ & 2.379 & 0.904 & $<0.001$ & 0.904 \\
\hline $\begin{array}{c}\text { Density, } \rho \& \\
\text { Initial velocity, } V_{f, 0} \\
\end{array}$ & 2.430 & 0.014 & 2.416 & 0.173 & $<0.001$ & 0.173 \\
\hline \multicolumn{7}{|c|}{ Burning firebrands (variable thickness) } \\
\hline $\begin{array}{l}\text { Flow velocity, } V_{\text {flow }} \& \\
\text { Incident angle, } \varphi\end{array}$ & 6.091 & 2.269 & 3.822 & 4.101 & 4.114 & -0.013 \\
\hline $\begin{array}{c}\text { Flow velocity, } V_{\text {flow }} \& \\
\text { Initial velocity, } V_{f, 0}\end{array}$ & 6.091 & 2.250 & 3.841 & 4.101 & 4.026 & -0.075 \\
\hline $\begin{array}{c}\text { Flow velocity, } V_{\text {flow }} \& \\
\text { Density, } \rho \\
\end{array}$ & 6.091 & 2.246 & 3.845 & 4.101 & 4.023 & -0.078 \\
\hline $\begin{array}{c}\text { Incident angle, } \varphi \& \& \\
\text { Initial velocity, } V_{f, 0} \\
\end{array}$ & 2.431 & 0.019 & 2.412 & 1.254 & 0.022 & 1.232 \\
\hline $\begin{array}{c}\text { Incident angle, } \varphi \& \\
\text { Density, } \rho\end{array}$ & 2.381 & $<0.001$ & 2.381 & 1.221 & $<0.001$ & 1.221 \\
\hline $\begin{array}{c}\text { Density, } \rho \& \\
\text { Initial velocity, } V_{\mathrm{f}, 0}\end{array}$ & 2.431 & 0.014 & 2.417 & 0.207 & 0.008 & 0.199 \\
\hline
\end{tabular}




\subsection{Effects of control parameters}

Firebrands transport is a complex proceedure combining both aerodynamic and combustion behaviours. Without considering the effects of combustion, the control parameters can be simplified into four: ambient flow velocity, initial particle velocity, density and incident angle. Building on the results presented in the previous section, the effects of these parameters are further investigated. Due to the limited space in this paper, the discussions focus on the trajectories from the variable-thicknessburning model with large Reynolds numbers, shown in Fig. 3.
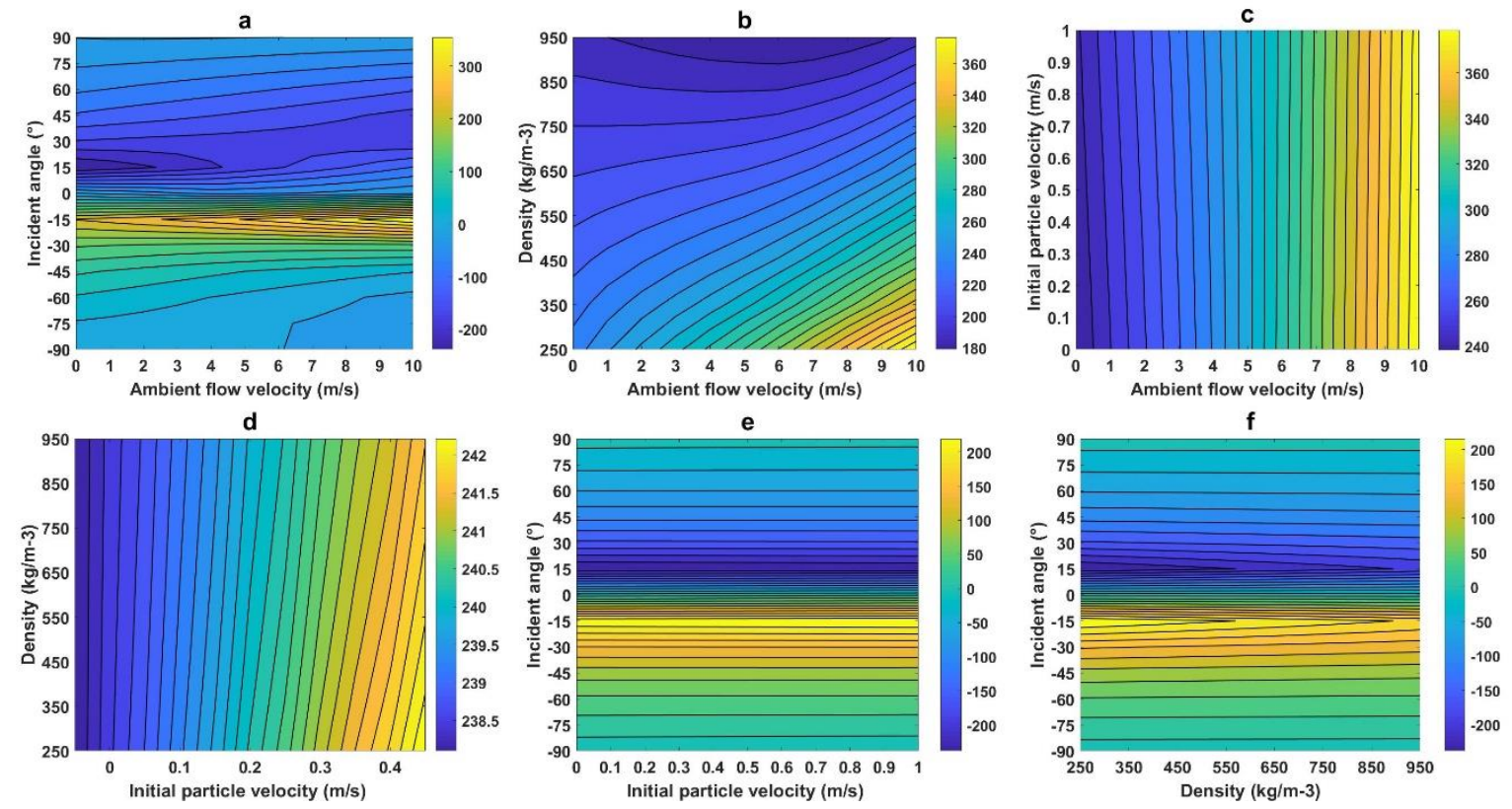

Figure 3 - Contour plots of lift effects of non-burning firebrands with various parameters.

Fig. 3 presents the contour plots for the differences in horizontal displacements for firebrands calculated with and without lift force, as functions of different parameters. Apart from the independent variables in each figure, the values for the other two parameters are given in Table 2. A complex dependence on the flow velocity and the incident angle can be observed in Fig. 3a, which shows the difference in the displacement is highly dependent on the incident angle, especially when it falls in the interval $\left[-30^{\circ}, 30^{\circ}\right]$. The propagations of firebrands are very sensitive to the incident angle and are increased for negative incident angles. With the increasing inertia due to larger density of a firebrand, the effects of the lift become more independent of the flow velocity, shown in Fig. 3b. However, it is clear that the effects of the lift depends more strongly on the flow velocity than the initial velocity, as is shown in Fig. 3c, and the latter in turn has stronger effects than the density, which can be observed from Fig. 3d. Above all, the incident angle has the most important effects. Apart from negative incident angles, large flow velocity and small firebrands density also enhance the lift effects on propagations.

Table 2 - Testing values of control parameters.

\begin{tabular}{cc}
\hline \hline Control Parameters & Testing values \\
\hline \hline Flow velocity, $V_{\text {flow }}$ & $10 \mathrm{~m} / \mathrm{s}$ \\
\hline Incident angle, $\varphi$ & $-15^{\circ}$ \\
\hline Initial velocity, $V_{\mathrm{f}, 0}$ & $1.0 \mathrm{~m} / \mathrm{s}$ \\
\hline Density & $250 \mathrm{~kg} / \mathrm{m}^{3}$ \\
\hline \hline
\end{tabular}




\subsection{Effects of the lift on trajectories}

Based on the above discussion, the effects of the ambient flow velocity and the incident angle deserve further investigation. The left panel of Fig. 4 shows the ratio between the horizontal displacements of the particle modelled with or without the lift force, calculated by the large Reynolds number model coupled with the variable-thickness burning model. It can be found that the result depends strongly on the incident angle. The lift increases the travel distances when the incident angle is negative (meaning the disk is tilted forward). The ratio peaks at an incident angle around $-15^{\circ}$. The peak value reaches up to 14 for small wind speed. It decreases to around 3 when the flow velocity is increased to $10 \mathrm{~m} / \mathrm{s}$. Even though the ratio decreases with the wind speed, the right panel in Fig. 4 shows that the absolute difference actually increases with the latter for incident angle between $-30^{\circ}$ and $0^{\circ}$, while it decreases between $-90^{\circ}$ and $-30^{\circ}$. Thus, at large $\mathrm{Re}$, the lift force has the potential to significantly increase the modelled propagation distances.
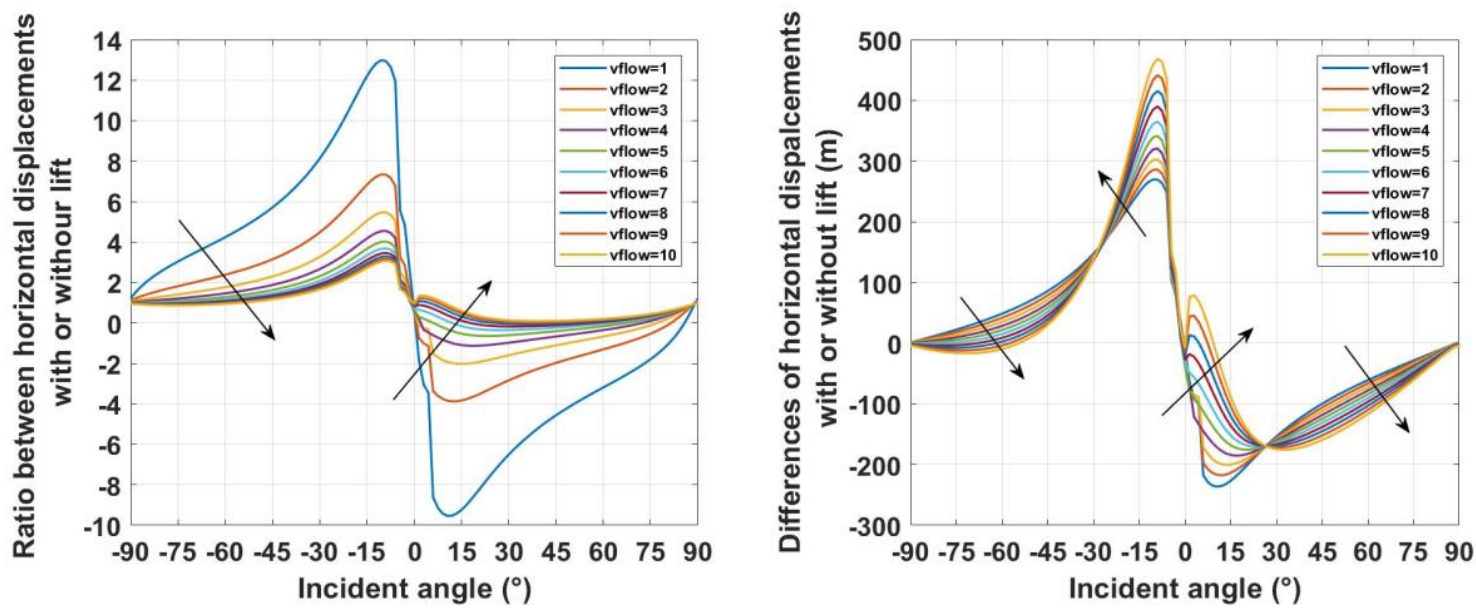

Figure 4 - Left: Ratio between horizontal displacement with or without lift; Right: Effects of lift on maximum distances.

\section{Conclusion}

The trajectories of both non-burning and burning firebrands are determined for three simplified models. A burning model is investigated where the variation of the thickness of the firebrand during combustion is considered. Parametric studies are performed to determine the effects of aerodynamic lift force. The maximum potential spotting distances at various parameters are calculated and expressed in terms of the Glide Ratios. The importance of the parameters involved, including Reynolds number, ambient flow velocity, incident angle, particle initial velocity and density of firebrand, are obtained and compared with each other.

It is found that the lift force has very significant effects on firebrand propagations. At large Reynolds numbers, the maximum spotting distance can be increased by up to $170 \%$ by the lift force for a firebrand released from $100 \mathrm{~m}$ in height. The lift effect strongly depends on incident angle. The peak value of the ratio between horizontal displacement with or without lift is found at $-15^{\circ}$ with a 14 times increase. The results highlight the importance of the aerodynamic lift force, and suggest that it should be included in order to estimate extreme spotting distances.

\section{Reference}

Albini, F. (1979). Spot fire distance from burning trees. Ogden, Utah: Intermountain Forest and Range Experiment Station, Forest Service, U.S. Dept. of Agriculture. 
Anthenien, R., Tse, S. and Carlos Fernandez-Pello, A. (2006). On the trajectories of embers initially elevated or lofted by small scale ground fire plumes in high winds. Fire Safety Journal, 41(5), pp.349-363.

Himoto, K. and Tanaka, T. (2005). Transport Of Disk-shaped Firebrands In A Turbulent Boundary Layer. Fire Safety Science, 8, pp.433-444.

Koo, E., Pagni, P., Weise, D. and Woycheese, J. (2010). Firebrands and spotting ignition in large-scale fires. International Journal of Wildland Fire, 19(7), p.818.

Lee, S. and Hellman, J. (1970). Firebrand trajectory study using an empirical velocity-dependent burning law. Combustion and Flame, 15(3), pp.265-274.

Muraszew, A., Fedele, J. and Kuby, W. (1977). Trajectory of firebrands in and out of fire whirls. Combustion and Flame, 30, pp.321-324.

Ortiz, X., Rival, D. and Wood, D. (2015). Forces and Moments on Flat Plates of Small Aspect Ratio with Application to PV Wind Loads and Small Wind Turbine Blades. Energies, 8(4), pp.24382453.

Sardoy, N., Consalvi, J., Porterie, B. and Fernandezpello, A. (2007). Modeling transport and combustion of firebrands from burning trees. Combustion and Flame, 150(3), pp.151-169.

Tarifa, C., Notario, P. and Moreno, F. (1965). On the flight paths and lifetimes of burning particles of wood. Symposium (International) on Combustion, 10(1), pp.1021-1037.

Tse, S. and Fernandez-Pello, A. (1998). On the flight paths of metal particles and embers generated by power lines in high winds - a potential source of wildland fires. Fire Safety Journal, 30(4), pp.333356.

Williams, F. (1985). Combustion theory. 2nd ed.

Woycheese, J., Pagni, P. and Liepmann, D. (1999). Brand Propagation From Large-Scale Fires. Journal of Fire Protection Engineering, 10(2), pp.32-44.

Yin, C., Rosendahl, L., Knudsen Kær, S. and Sørensen, H. (2003). Modelling the motion of cylindrical particles in a nonuniform flow. Chemical Engineering Science, 58(15), pp.3489-3498.

Zastawny, M., Mallouppas, G., Zhao, F. and van Wachem, B. (2012). Derivation of drag and lift force and torque coefficients for non-spherical particles in flows. International Journal of Multiphase Flow, 39, pp.227-239. 